NATIONAL LABORATORY

MANAGED BY UT-BATTELLE

FOR THE DEPARTMENT OF ENERGY

\title{
Analysis of the Johns Hopkins Neutron Background Measurements
}

August 2011

Prepared by

P. A. Hausladen

S. M. McConchie

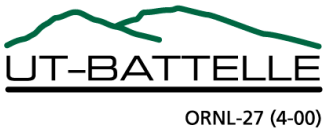




\section{DOCUMENT AVAILABILITY}

Reports produced after January 1, 1996, are generally available free via the U.S. Department of Energy (DOE) Information Bridge.

Web site http://www.osti.gov/bridge

Reports produced before January 1, 1996, may be purchased by members of the public from the following source.

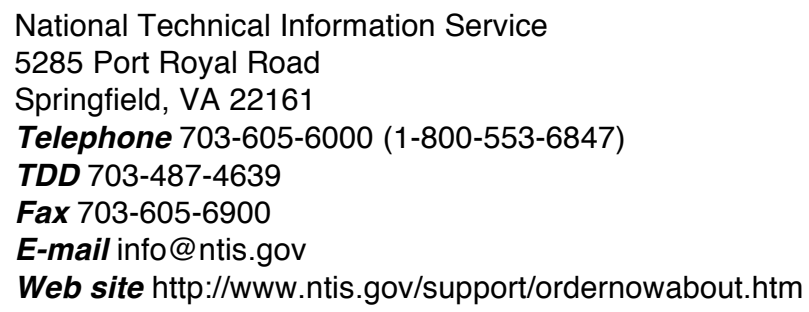

Reports are available to DOE employees, DOE contractors, Energy Technology Data Exchange (ETDE) representatives, and International Nuclear Information System (INIS) representatives from the following source.

Office of Scientific and Technical Information

P.O. Box 62

Oak Ridge, TN 37831

Telephone 865-576-8401

Fax 865-576-5728

E-mail reports@osti.gov

Web site http://www.osti.gov/contact.html

This report was prepared as an account of work sponsored by an agency of the United States Government. Neither the United States Government nor any agency thereof, nor any of their employees, makes any warranty, express or implied, or assumes any legal liability or responsibility for the accuracy, completeness, or usefulness of any information, apparatus, product, or process disclosed, or represents that its use would not infringe privately owned rights. Reference herein to any specific commercial product, process, or service by trade name, trademark, manufacturer, or otherwise, does not necessarily constitute or imply its endorsement, recommendation, or favoring by the United States Government or any agency thereof. The views and opinions of authors expressed herein do not necessarily state or reflect those of the United States Government or any agency thereof. 
Global Nuclear Security Technology Division

\section{ANALYSIS OF THE JOHNS HOPKINS NEUTRON BACKGROUND MEASURMENTS}

P. A. Hausladen and S. M. McConchie

Date Published: August 2011

Prepared by

OAK RIDGE NATIONAL LABORATORY

Oak Ridge, Tennessee 37831-6283

managed by

UT-Battelle, LLC

for the

U.S. DEPARTMENT OF ENERGY

under contract DE-AC05-00OR22725 


\section{CONTENTS}

\section{Page}

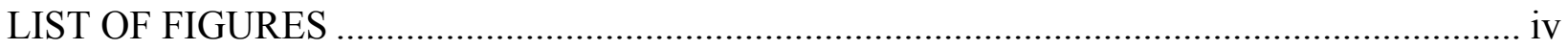

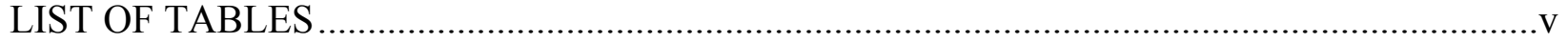

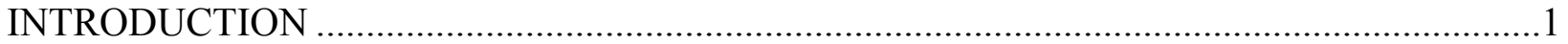

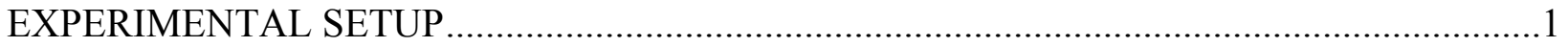

RESULTS … -

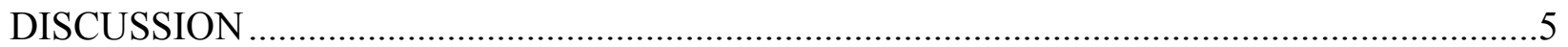

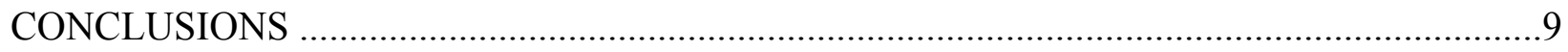

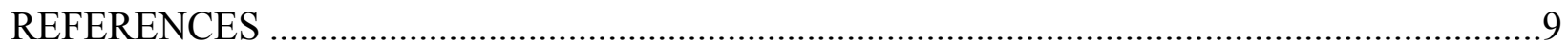




\section{LIST OF FIGURES}

Figure

Page

1. Photograph showing the test stand consisting of two shelves ........................................ 2

2. Photograph showing the configuration of ${ }^{3} \mathrm{He}$ detectors on Deck $\mathrm{C}$ of the

Cape Washington

3. Neutron time correlation distributions for the various steel overburdens in the test range and the Cape Washington decks

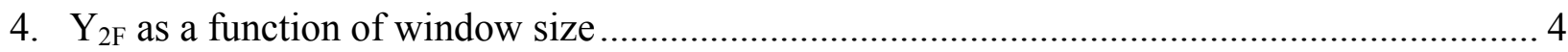

5. Singles and doubles rates plotted as a function of steel overburden................................ 4

6. The expected relative production of neutrons in iron plotted as a function of incident cosmic-ray neutron energy.

7. Estimated induced neutron distributions from spallation for different energy ranges in the cosmic-ray neutron spectrum.

8. (Left) solid angle subtended by the neutron detectors for neutrons induced at different points in the steel, and (right) solid angle subtended by the neutron detectors for pairs of neutrons induced at different points in the detector

9. (Left) singles and (right) doubles rates as a function of steel overburden for (black) measured data, (red) expected rate from known cosmic-ray neutron rates, and (blue) expected rate from known cosmic-ray neutron and proton rates 


\section{LIST OF TABLES}

Table

1. Steel overburden for each deck of the Cape Washington ............................................... 3

2. Singles and doubles rates tabulated for each measurement ............................................. 4 


\section{INTRODUCTION}

Shipboard neutron measurements to look for the presence of illicit special nuclear material (SNM) can be used in response to specific intelligence or can potentially be used for long-dwell measurements on cargo vessels as screening in transit. In either case, sensitivity for a true source is limited by variability in the local value of neutron background rates at different locations in a ship. These background rates are determined by competition between creation of roughly fission-spectrum neutrons in energetic spallation reactions of high-energy cosmic rays impinging on steel in the ship and shielding by cargo, and can vary an order of magnitude throughout a vessel. On the other hand, ground-based measurements of cosmic-ray-induced neutrons by Gordon et al. [1] found that the shape of the neutron spectrum above $\sim 5 \mathrm{MeV}$ did not vary significantly with altitude, geomagnetic cutoff, or solar modulation. As such, the local value of the neutron background may be predictable in relation to the high-energy tail of the neutron spectrum, either by direct measurement of the high-energy component or by measurement of correlated neutron backgrounds originating from reactions induced by the high-energy component. To gain a better understanding of neutron backgrounds (and correlated neutron backgrounds) aboard a ship, Johns Hopkins University Applied Physics Laboratory (JHU/APL) performed neutron background measurements aboard the Cape Washington roll-on/roll-off (Ro-Ro) cargo vessel (while empty). To aid in the understanding of these measurements, additional measurements were performed in a controlled geometry at a terrestrial test stand where steel overburden could be varied to span roughly the range of overburden encountered on the various decks of the Cape Washington. The present work reports on analysis of the JHU/APL test stand and Cape Washington neutron background data performed by Oak Ridge National Laboratory.

\section{EXPERIMENTAL SETUP}

Neutron counting was performed by JHU/APL at the test stand and aboard the Cape Washington using four sets of neutron detectors. Each set of neutron detectors consisted of five 20 -atm ${ }^{3} \mathrm{He}$ proportional counters whose active dimensions measure $2.5 \mathrm{~cm}$ in diameter by $13.1 \mathrm{~cm}$ long. Each set was enclosed in a high-density polyethylene (HDPE) box having $3.5 \mathrm{~cm}$ wall thickness and whose outer dimensions measure $22.9 \times 24.7 \times 11.4 \mathrm{~cm}$. Each HDPE box was in turn packed in foam inside a pelican case having dimensions $40.6 \times 33.0 \times 17.8 \mathrm{~cm}$. For the measurements with the test stand, the detectors were placed adjacent to each other such that they made an aggregate $40.6 \times 132.1 \times 17.8 \mathrm{~cm}$ detector. Each neutron hit was recorded "list mode" to a precision of $50 \mathrm{~ns}$. During the measurements, one of the detectors was double pulsing, so data from only three of the detectors was provided to ORNL.

The test stand consisted of a table with two shelves. The detectors were placed on the lower shelf such that the tops of the detectors were about $5 \mathrm{~cm}$ below the top shelf. Steel could be stacked on the top shelf of the test stand in 1 in. $(2.54 \mathrm{~cm})$ thickness increments, between $2.54 \mathrm{~cm}$ and $15.2 \mathrm{~cm}$, and covering an area of $1.67 \mathrm{~m}^{2}$. With the maximum steel thickness, the total mass of steel amounted to $2000 \mathrm{~kg}$. A photograph of the test stand is shown in Fig. 1. 


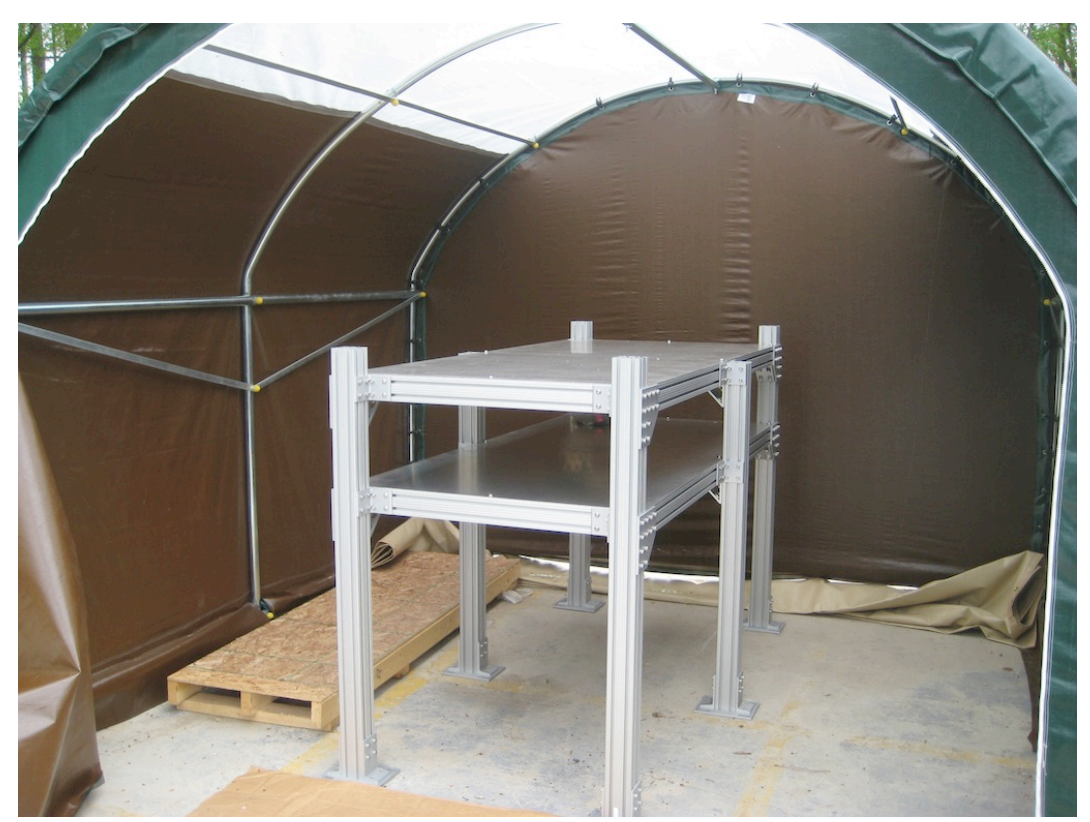

Fig. 1. Photograph showing the test stand consisting of two shelves. Varying thicknesses of steel were placed on the top shelf, and the detectors were placed on the bottom shelf.

On the Cape Washington, the four detectors were arranged in a square pattern in which the detectors were separated from each neighbor by $140 \mathrm{~cm}$. This arrangement was placed on each of six decks and neutron counts recorded. A photograph of the detector configuration on the $\mathrm{C}$ deck is shown in Fig. 2. The overburden of steel corresponding to each of the decks is listed in Table 1.

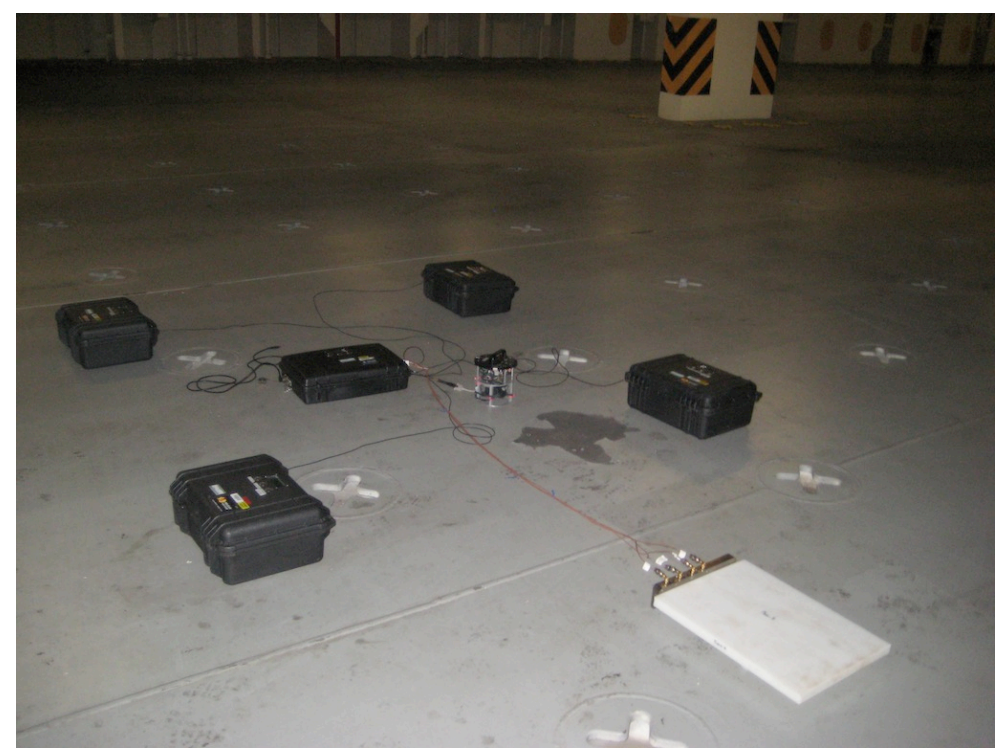

Fig. 2. Photograph showing the configuration of ${ }^{3} \mathrm{He}$ detectors on Deck $\mathrm{C}$ of the Cape Washington. The data for three of the four black detectors shown in the square configuration were provided for analysis. Each detector was separated from its closest neighbor by $140 \mathrm{~cm}$. 
Table 1. Steel overburden for each deck of the

Cape Washington

\begin{tabular}{ll}
\hline Deck & Steel overburden (in.) \\
\hline Accommodation & 0.5 \\
\hline $\mathrm{C}$ & 1.5 \\
\hline 8 & 2.5 \\
\hline $\mathrm{B}$ & 3.5 \\
\hline $\mathrm{A}$ & 5.5 \\
\hline 1 & 7.5 \\
\hline
\end{tabular}

\section{RESULTS}

The data for the test stand and the Cape Washington were analyzed to determine the neutron rates and time correlation distributions. The time distribution of coincidences for (left) the test stand data of background and six steel overburden thicknesses and (right) the Cape Washington data for the 1, A, B, 8, C, and Accommodation decks are shown in Fig. 3. When the coincidence distribution shown is integrated and scaled by the singles rate, it is known as the $\mathrm{Y}_{2 \mathrm{~F}}$ (Feynman variance-to-mean). In this case it is shown for each data set as a function of coincidence window size for window sizes from $1 \mu \mathrm{s}$ to $1 \mathrm{~ms}$. The $\mathrm{Y}_{2 \mathrm{~F}}$ plots are shown in Fig. 4. Fitting the time dependence and magnitude of the $\mathrm{Y}_{2 \mathrm{~F}}$ distributions determines the time constant of the detectors as well as asymptotic values of the $\mathrm{Y}_{2 \mathrm{~F}}$ in the limit of long coincidence windows. In the test stand as well as the Cape Washington data, the time constant was determined to be $\sim 60 \mu \mathrm{s}$. The doubles rates were determined by multiplying the asymptotic values of the $\mathrm{Y}_{2 \mathrm{~F}}$ with the corresponding singles rates. The singles rates and doubles rates are tabulated in Table 2 for all measurements and are plotted as a function of steel overburden in Fig. 5.
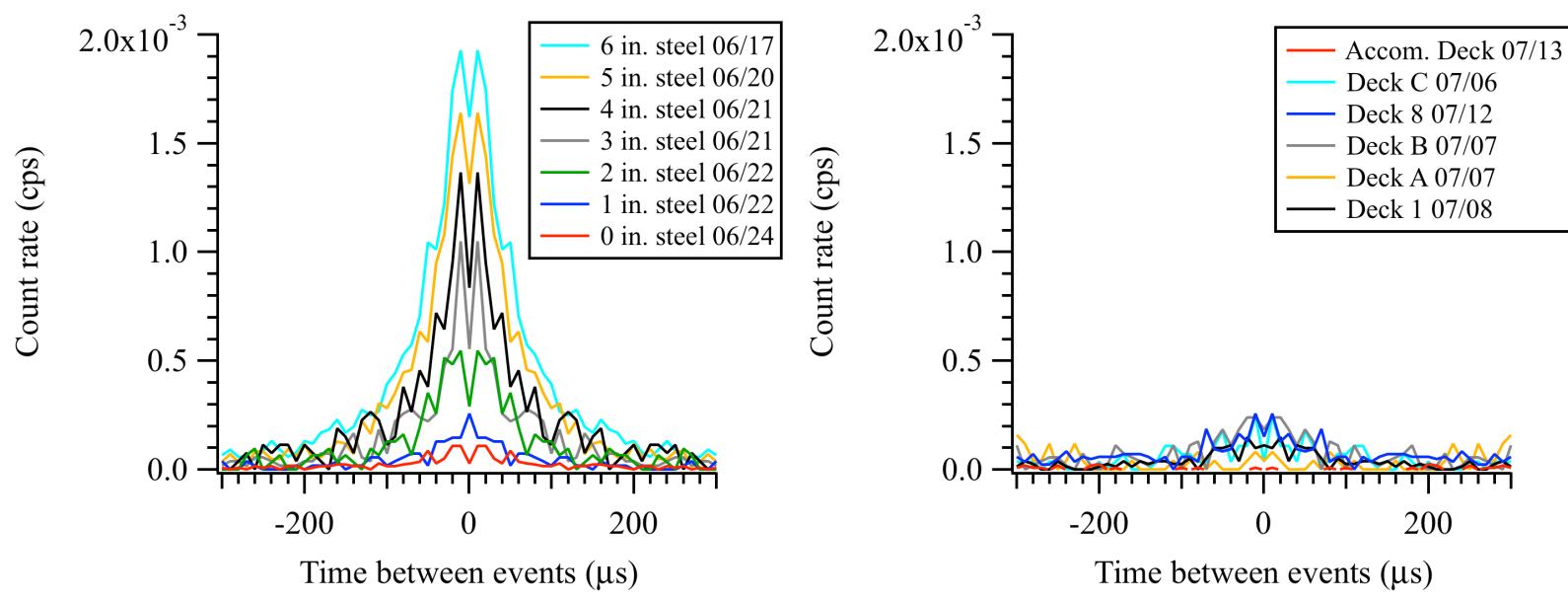

Fig. 3. Neutron time correlation distributions for the various steel overburdens in the test range and the Cape Washington decks. The distributions are normalized to the total measurement time. 

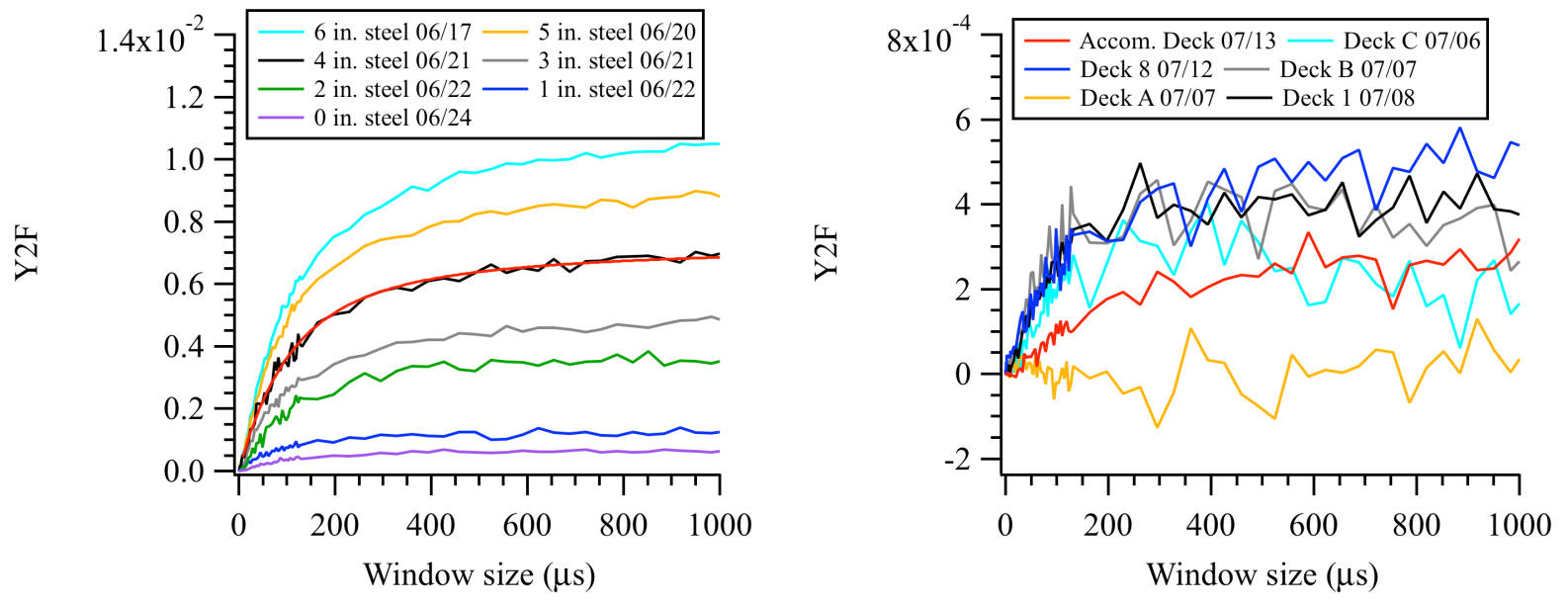

Fig. 4. $Y_{2 F}$ as a function of window size. The $Y_{2 F}$ fit of the $4 \mathrm{in}$. steel overburden is shown.

Table 2. Singles and doubles rates tabulated for each measurement

\begin{tabular}{llll}
\hline $\begin{array}{l}\text { Test stand } \\
\text { overburden (in.) }\end{array}$ & Time (s) & Singles rate (cps) & Doubles rate (cps) \\
\hline 0 & 138,872 & 0.79 & $6.4 \times 10^{-4}$ \\
\hline 1 & 54,763 & 0.88 & $1.0 \times 10^{-3}$ \\
\hline 2 & 31,125 & 0.95 & $3.5 \times 10^{-3}$ \\
\hline 3 & 54,304 & 1.01 & $4.9 \times 10^{-3}$ \\
\hline 4 & 26,378 & 1.07 & $8.0 \times 10^{-3}$ \\
\hline 5 & 85,319 & 1.16 & $1.1 \times 10^{-2}$ \\
\hline 6 & 153,175 & 1.23 & $1.4 \times 10^{-2}$ \\
\hline Cape Washington Deck & & $4.4 \times 10^{-4}$ \\
\hline Accommodation & 106,498 & 1.40 & $5.0 \times 10^{-4}$ \\
\hline C & 27,982 & 1.86 & $1.1 \times 10^{-3}$ \\
\hline 8 & 85,570 & 2.01 & $8.8 \times 10^{-4}$ \\
\hline B & 54,463 & 2.16 & $1.6 \times 10^{-5}$ \\
\hline A & 25,163 & 1.77 & $6.2 \times 10^{-4}$ \\
\hline 1 & 81,277 & 1.39 & \\
\hline
\end{tabular}
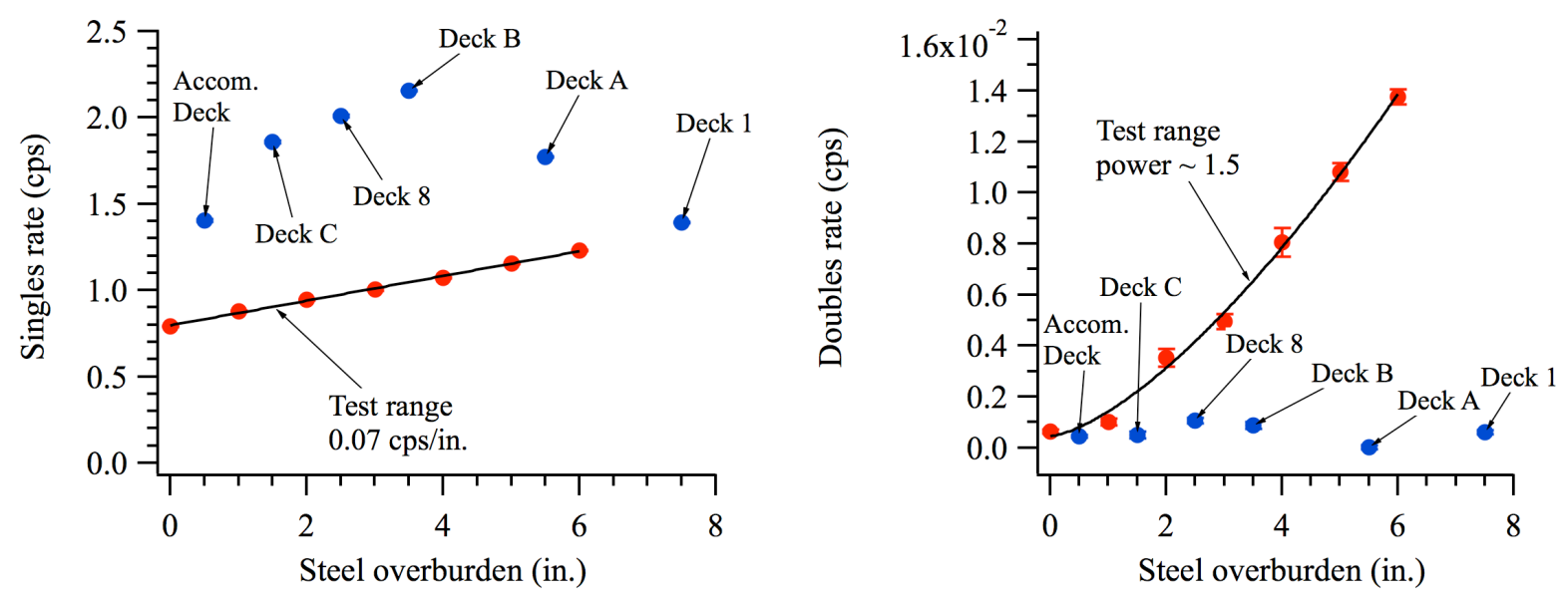

Fig. 5. Singles and doubles rates plotted as a function of steel overburden. 
For the test stand data, the neutron singles rate increases linearly with the thickness of steel overburden at a rate of 0.07 neutrons $\mathrm{s}^{-1}$ per inch of steel. The rate of neutron coincidences, or doubles rate, increases faster than linearly. A power-law fit to the doubles data indicated that the number of doubles increased like thickness to the power 1.5. No physical meaning is ascribed to the particular value of the power, but its value greater than unity indicates that the addition of steel thickness allows the showers of neutrons induced in the steel by cosmic-rays not just to become more numerous, but also longer. From 1 to 6 in. of steel, the doubles rate increases about an order of magnitude.

For the Cape Washington data, the observed neutron singles rate on all the decks is greater than the maximum observed at the test stand. However, the neutron doubles rates are all approximately consistent with the test stand data with no steel overburden. The maximum neutron rate is observed at the center of the ship, indicating that the steel below as well as the steel above the detectors contributes to the observed rate. The full areal density of the empty Cape Washington is not a significant attenuator to neutrons, so it is reasonable to suppose that the creation of spallation neutrons happens at an approximately constant rate throughout the ship and that much of the neutron production is emitted isotropically. Under such conditions, the neutron rate should peak in the center of the vessel. The neutron doubles also appear to weakly peak toward the center of the ship.

\section{DISCUSSION}

Energetic cosmic rays at sea level consist primarily of muons and neutrons. The muons have a mean energy of $4 \mathrm{GeV}$ and a rate of approximately 150 muons $\mathrm{m}^{-2} \mathrm{~s}^{-1}$ [2]. High-energy neutrons above $100 \mathrm{MeV}$ occur at a rate of approximately 16 neutrons $\mathrm{m}^{-2} \mathrm{~s}^{-1}[1]$. Because neutrons do not have charge, neutrons have significant numbers down to thermal energies. Cosmic-ray protons, on the other hand, are largely greater than $1 \mathrm{GeV}$ in energy with trajectories close to vertical $[2,3]$. The rate of such protons is approximately $0.6 \mathrm{~m}^{-2} \mathrm{~s}^{-1}$ at sea level. While highenergy muons are the most numerous, muon-induced spallation and negative muon capture reactions are not a significant source of neutrons at sea level [4]. Most induced neutrons originate from spallation reactions induced by energetic $(\sim 100 \mathrm{MeV})$ neutrons.

The spallation process is normally understood to consist of an energetic projectile incident on a nucleus having a number of successive collisions with distinct nucleons as it traverses the nucleus and ejecting energetic "cascade" neutrons followed by emission of "evaporation" neutrons as the target nucleus de-excites. For incident neutrons in the $200 \mathrm{MeV}$ to $2 \mathrm{GeV}$ energy range, the average number of induced neutrons on targets with mass numbers greater than 40 can be estimated from the rule of thumb $\langle n\rangle=(0.0833+0.0317 \ln (E / 1000)) A$, where $E$ has units $\mathrm{MeV}$ [5]. Using this estimate of neutron number combined with the parameterization of neutron fluence found in Gordon et al., the relative number of neutrons induced by spallation reactions can be estimated as a function of incident neutron energy. This estimate is shown in Fig. 6. 


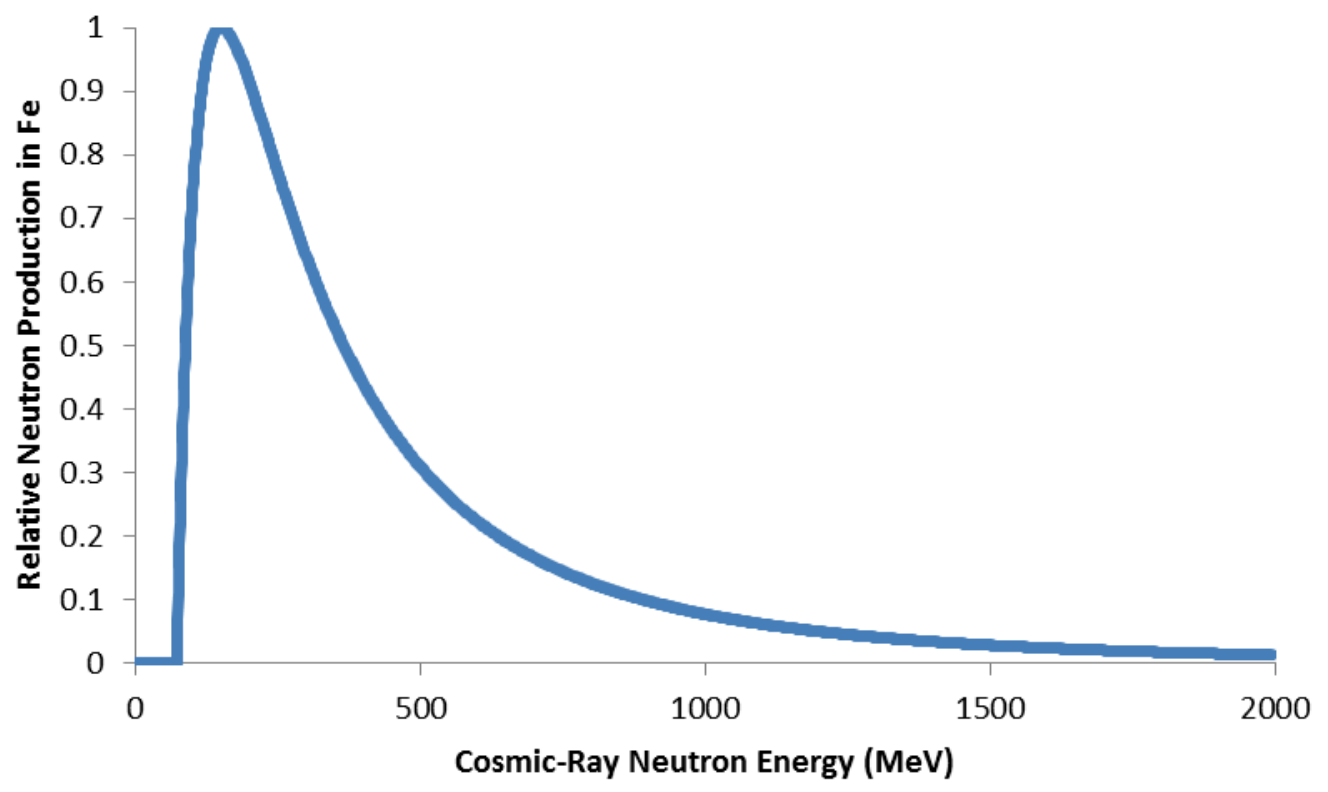

Fig. 6. The expected relative production of neutrons in iron plotted as a function of incident cosmic-ray neutron energy.

It can be seen from the figure that the largest contribution to induced neutrons comes from reactions induced by $\sim 150 \mathrm{MeV}$ neutrons. Although the induced multiplicity at this energy is low, the cosmic-ray neutrons having this incident energy are sufficiently numerous to compensate and make this energy range most probable. The low-energy behavior of the estimated induced neutron multiplicity (becoming negative below $\sim 70 \mathrm{MeV}$ ) is not physical, so energies below $\sim 70 \mathrm{MeV}$ were not calculated.

It is possible to estimate the expected number of detected neutrons and neutron coincidences using an extremely simplified model where high-energy neutrons pass through a thickness of steel and induce reactions releasing neutrons whose number for a particular incident energy is distributed about the average given by the above rule of thumb and whose probability is weighted by the probability of an initiating neutron having that incident energy. The estimated induced-neutron distributions where the incident neutrons are broken into five energy bins is shown in Fig. 7, along with the sum over all incident energies. 


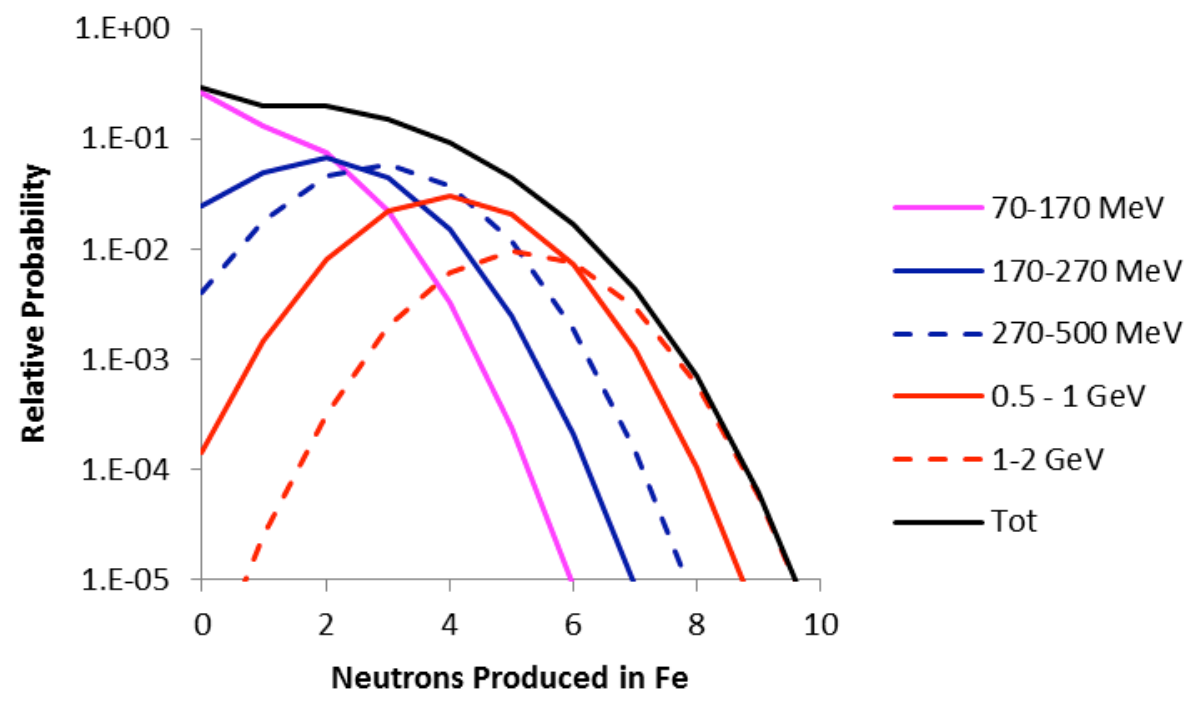

Fig. 7. Estimated induced neutron distributions from spallation for different energy ranges in the cosmic-ray neutron spectrum.

To estimate the detected number of neutrons, the reaction cross section and neutron detector efficiency also need to be known. The cross section for spallation reactions can be estimated as the "hard sphere" area of ${ }^{56} \mathrm{Fe}$, or 0.66 barns. This hard-sphere cross section gives a mean free path in steel of about $18 \mathrm{~cm}$, slightly longer than the largest thickness of steel studied. The average neutron efficiency for neutrons induced in the steel plate in the test stand configuration was calculated using the average solid angle subtended by the HDPE box and an assumed $20 \%$ intrinsic efficiency for neutrons incident on the HDPE box. It is worth noting that the usual assumption of having "a detector efficiency" is a poor approximation when counting neutrons from such an extended source. In the test stand configuration, for instance, approximately half of the detected neutrons originate in only $20 \%$ of the area of steel plate. For detected coincidences of neutrons originating at a common point, half of these originate in only $10 \%$ of the area of the steel plate. A picture of the solid angle for (left) one and (right) two neutrons as a function of the position on the steel plate is shown in Fig. 8. Nonetheless, the average efficiency to neutrons originating in the steel was calculated to be 0.0085 .
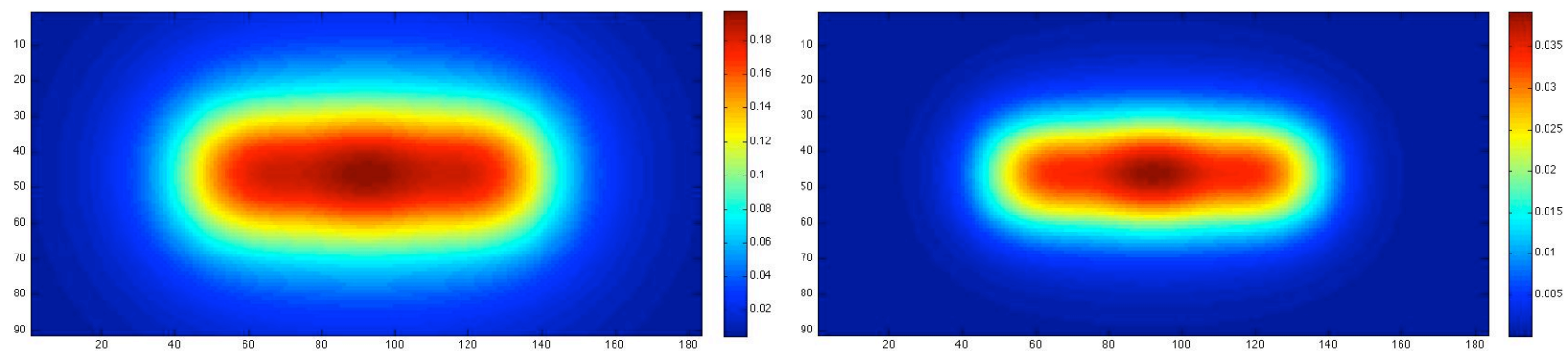

Fig. 8. (Left) solid angle subtended by the neutron detectors for neutrons induced at different points in the steel, and (right) solid angle subtended by the neutron detectors for pairs of neutrons induced at different points in the detector. 
Using the combination of cross section, neutron detector efficiency, and induced multiplicity distributions shown in Fig. 7, the distribution of neutrons produced in neutron-induced cascades was calculated in a toy Monte Carlo calculation, and the number of detected neutron singles and doubles extracted for different thicknesses of steel. The resulting predictions are compared to measured data in Fig. 9 for (left) induced-neutron singles and (right) induced-neutron doubles for cascades initiated by (blue) cosmic ray neutrons and protons.
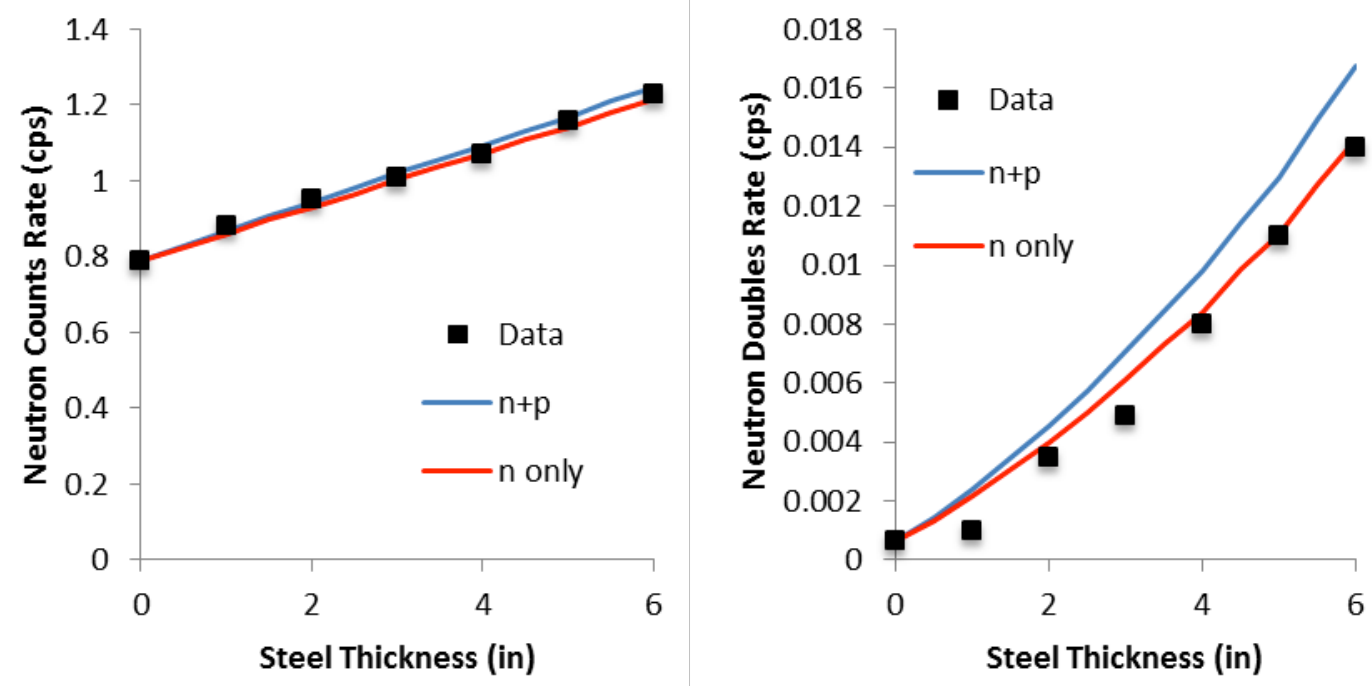

Fig. 9. (Left) singles and (right) doubles rates as a function of steel overburden for (black) measured data, (red) expected rate from known cosmic-ray neutron rates, and (blue) expected rate from known cosmic-ray neutron and proton rates.

To indicate the relative importance of neutron-induced production vs. proton-induced production, the neutron-induced component is shown separately in red. This level of agreement for such a simple model is almost certainly accidental. However, it does indicate that a simple understanding of the induced neutrons is possible for relatively thin objects, such as the 6 in. thickness of steel or the empty Cape Washington. It is important to note that the reported simulations were for single cosmic-ray neutrons or protons incident on the steel. Multiple neutrons and protons from a cosmic-ray shower incident on the same area of steel at the same time would produce larger cascades of induced neutrons, but this is not required to account for the observed number of coincidences. As such, the average number of high-energy nucleons from the same cosmic-ray shower incident on a square meter of steel is smaller than one, or equivalently, the average distance between neutron-producing interactions of distinct cosmic rays in the same shower may be a few meters or so. As such, for steel surfaces that are large but far away, the coincidence efficiency drops faster than additional neutrons are added from additional area available to interact with the cosmic-ray shower. In fact, an average areal density of incident cosmic-ray neutrons less than 0.3 is sufficient to explain the lack of observed coincidences on the Cape Washington. 


\section{CONCLUSIONS}

For the test stand data, measured rates of neutrons induced in steel by incident high-energy cosmic rays are in good agreement with calculated neutron production rates based on reported cosmic-ray fluxes. The induced neutrons originate primarily from spallation reactions induced by cosmic-ray neutrons with energies of order $100 \mathrm{MeV}$. Neutrons induced on the Cape Washington can be similarly understood provided one accounts for neutron production in steel both above and below the deck of the detectors. The lack of induced doubles on the Cape Washington can be understood from solid-angle arguments given that interactions induced by different cosmic rays in the same shower are on average separated by a few meters. Given the range of induced neutron singles and doubles rates as well as the lack of higher-order coincidences, it is doubtful that the background singles rate can be predicted from background multiples.

\section{REFERENCES}

[1] M. S. Gordon et al., IEEE Trans. Nucl. Sci. 51, 3427 (2004).

[2] K. Nakamura et al. (Particle Data Group), J. Phys. G 37, 075021 (2010) and 2011 partial update for the 2012 edition.

[3] S. Roesler et al., Rad. Prot. Dosim. 98, 367 (2002).

[4] V. A. Kudryavtsev et al., Nucl. Inst. Meth. A 505, 688 (2003).

[5] J. Cugnon et al., Nucl Phys A 625, 729 (1997). 